\title{
Sensory characteristics of structured guava (Psidium guajava): comparison of optimized descriptive profile, cata and sensory acceptance methods
}

\author{
Juliana Nascimento da COSTA ${ }^{1}$, Samuel Almeida BRITO², Amanda Rodrigues LEAL ${ }^{1}$, \\ Delane da Costa RODRIGUES ${ }^{1}$, Luís Gustavo Lima NASCIMENTO ${ }^{1}$, Raimundo Wilane FIGUEIREDO ${ }^{1}$, \\ Paulina MATA ${ }^{3}$, Paulo Henrique Machado de SOUSA ${ }^{1,2 *}$ (D)
}

\begin{abstract}
This work aimed a sensory characteristics of structured guava elaborated with hydrocolloids agar and combinations of LA and HA gellan. The methods used were Optimized Descriptive Profile (ODP), CATA and Sensory Acceptance Tests. For the ODP, 18 semi-trained judges selected 12 sensory attributes and evaluated the samples using $9 \mathrm{~cm}$ unstructured scales. Sensory acceptance and CATA tests were performed by 100 untrained panelists. Sensory tests expressed medium acceptability indexes and similar results for all samples. The highest frequency CATA attributes were Homogeneous, Brightness, Pinkish red color, Guava aroma and Sour taste. The characteristics from ODP were Brightness, Sweet taste, Sour taste, Guava flavor, Firm and Sandy texture. Comparing the three methods, in the CATA and sensory acceptance, tasters did not identify differences between the samples in relation to the type of hydrocolloid, but with the ODP method they could achieve this.
\end{abstract}

Keywords: hydrocolloids; structured fruit; sensory evaluation.

Practical Application: Sensory analysis of guava structured elaborated with agar and gellan gum.

\section{Introduction}

New trends in the food industry require the development of innovative products consistent with a healthy diet. However, it is difficult to obtain a product that maintains the nutritional and sensorial characteristics of a fresh food (Danalache et al., 2015). In this sense a structured fruit appears; and it is defined as a food product obtained by gelling the fruit pulp using low concentrations of hydrocolloids. These are responsible for binding water and providing structure to products having good texture, flavor, appearance and nutritional (Azoubel at al., 2011). Agar, also known as agar-agar or agarose, is a hydrocolloid, well known by the food industry, extracted from various genera and species of red seaweed and consists of a heterogeneous mixture of two polysaccharides, agarose and agaropectin. It forms non-absorbable, non-fermentable and nontoxic gels (Petrovski \& Tillett, 2012). Gellan, or gellan gum, is a hydrocolloid, produced by the bacterium Sphingomonas elodea. It is available in two forms with different characteristics: low acyl (LA) and high acyl (HA), and it shows thickener, emulsifier and stabilizer properties useful for a wide range of food systems (Chandrasekaran \& Radha, 1995). The process of development of new products is an indispensable segment of the foodstuff industry for the survival of companies and for market economies. The main objective in the development and improvement of products is to meet the needs and acceptance of consumers (Bonneau et al., 2018). The use of descriptive sensory methods with consumers aims to provide valid and reliable information on the sensory characteristics of food products. The Optimized Descriptive Profile (ODP) is a fast method for sensory description of foods, in which tasters with low training are involved. In this test, the judges receive all samples and evaluate a single attribute per session. They indicate intensity by marking in unstructured $9 \mathrm{~cm}$ scales anchored at the extremes by the terms "weak" and "strong". Thus, it allows the classification of the products through a comparative evaluation between the analyzed samples, and a quantitative characterization of the sensory attributes (Silva et al., 2012, 2014). Check-All-That-Apply (CATA) has been widely used for sensory characterization of food products. It consists of a list of words or phrases in which respondents select all options applicable to the analyzed sample. The list of words should be known to the consumers and less technical/specific, favoring the effectiveness of the method. The test can be performed by untrained people and it is not demanding for consumers, with a minimum recommendation of $\mathrm{N}=60$ to 80 consumers. (Meyners et al., 2014; Vidal et al., 2015; Avery \& Joseph, 2019; Jaeger et al., 2019). Some recent studies have used the CATA method to characterize products such as hot and cold foods and beverages (Pramudya \& Seo, 2018), solid products requiring oral processing prior to swallowing (Vidal et al., 2019) and vegetable and berry beverages, where the authors demonstrated the association between consumer's emotions and taste (Waehrens et al., 2018). The aim of this study was to evaluate the sensory profile of guava fruit pulp structured using agar and LA and HA gellan gum in different proportions. Three different methodologies - Sensory Acceptance tests, CATA and ODP - were used and the results compared. 


\section{Materials and methods}

\subsection{Raw material}

Fruit bars were prepared with frozen guava pulp, provided by a fruit processing company located in the city of Fortaleza - CE, Brazil. Hydrocolloids used for the preparation of the samples were agar commercialized by Sosa ${ }^{\circledR}$ and HA and LA gellan gum produced by CP Kelco ${ }^{\circledast}$.

\subsection{Preparation of structured fruits}

For the preparation of the structured guava samples the pulp was thawed to room temperature (around $25^{\circ} \mathrm{C}$ ). Subsequently, the hydrocolloids (agar, and LA and HA gellan) were separately weighed as required to obtain predetermined concentrations. They were then added to the thawed pulp in a food processor (Termomix, PMS-018, Yammi) at a temperature of approximately $85 \pm 2{ }^{\circ} \mathrm{C}$. The samples were kept under stirring for about $30 \mathrm{~s}$ until boiling. This process allows the complete dispersion and dissolution of the hydrocolloid, according to the methodology described by Danalache et al. (2016).

\subsection{Selection of hydrocolloids concentration}

60 untrained panelists of both genders and aged from 18 to 65 years old, evaluated structured fruit with a range of agar concentrations $(0.25 \%, 0.5 \%, 0.75 \%$ and $1.0 \% \mathrm{w} / \mathrm{v})$. They were randomly recruited at the Institute of Culture and Art (ICA) of the Federal University of Ceara. The acceptance analysis was performed in individual cabins, under controlled lighting, noise and temperature conditions. Structured fruits, at the temperature of $7^{\circ} \mathrm{C}$, were cut into pieces of approximately $4 \mathrm{~cm}^{2}$ and served in $50 \mathrm{~mL}$ plastic cups. The cups were coded with random three-digit numbers. Water was provided to clean the palate between samples. A 9-point hedonic scale, ranging from "dislike extremely" (1) to "liked extremely" (9), was used to evaluate the acceptance of texture (Stone \& Sidel, 2004). The study protocol was approved by the Research Ethics Committee under protocol number 1.829.642.

\subsection{Sensory evaluation: acceptance testing}

100 untrained panelists of both gender (63 women and 37 men), aged from 18 to 65 years old, evaluated four samples produced using guava pulp and $0.75 \% \mathrm{w} / \mathrm{v}$ concentration of a range of hydrocolloids (agar, LA100/HA0, LA75/HA25 and LA50/HA50). The analysis was performed using the same methodology described above. A scale of 5 points was used to analyze the consumption intent, where 1 is the minimum score (I would not eat) and 5 the highest score (I would always eat) (Stone \& Sidel, 2004).

\subsection{Check-All-That-Apply (CATA) question}

After the acceptance test, the 100 panelists were asked to complete a CATA questionnaire composed of 28 descriptive terms related to sensory and non-sensory characteristics of the structured guava fruit. The terms were selected based on preliminary tests made with possible panelists and a discussion with trained panelists. The consumers were asked to mark in the CATA form the terms that best described the features for each structured guava fruit sample. The frequency of use of each term reflects the number of users who used it, according to Vidal et al. (2015).

\subsection{Optimized descriptive profile}

27 potential panelists were subjected to basic taste identification screening tests in which they were asked to recognize four different tastes, salty $(\mathrm{NaCl} 4 \mathrm{~g} / \mathrm{L})$, sweet $(\mathrm{C} 12 \mathrm{H} 22 \mathrm{O} 1124 \mathrm{~g} / \mathrm{L})$, sour (C6H8O7 $1 \mathrm{~g} / \mathrm{L})$ and bitter (C76H52O46 $0.5 \mathrm{~g} / \mathrm{L})$ according to Faria \& Yotsuyanagi (2008). The panelists who scored at least $75 \%$ of the responses were approved to the next stage, as by Meilgaard et al. (2006). 21 tasters reached scores to move on to the next stage and were submitted to four triangular test sessions, in which each one received three samples, two similar and a different one, and was asked to identify the different one. In the first triangular test, one of the samples was formulated using $0.75 \%$ LA gellan and a mixute of 1:1 guava pulp and water. The other sample was formulated using the same concentration of LA gellan and only guava fruit pulp. In the second triangular test, all samples were prepared using only guava pulp and $0.75 \%$ LA gellan, but $5 \% \mathrm{w} / \mathrm{v}$ of sugar was added to one of the samples. The third and fourth triangular tests were performed using samples of guava pulp with different concentrations of LA gellan. A total of 18 judges were selected through this process (10 males and 8 females), which is a number considered enough for the ODP method (Silva et al., 2012). The 18 pre-selected panelists participated of a preliminary group session for familiarization with the reference samples and the descriptive terms. After discussion and elimination of similar terms by consensus, a list of 12 sensory attributes was elaborated. The evaluation of structured guava fruits was performed using the attribute-by-attribute protocol therefore only one attribute was evaluated per session. The evaluation was performed using the Optimized Descriptive Profile (ODP) on a $9 \mathrm{~cm}$ unstructured attribute scale with intensity varying from 1 (very weak) to 9 (very strong) (Silva et al., 2012). Each panelist simultaneously received four structured guava samples (LA100/HA0, LA75/HA25, LA50/HA50 agar) in three replicates, was performed using the same methodology described above. Panelists were invited to compare the products with the reference materials and rate the intensity of the attribute for each sample on the scale. There were 12 evaluation sessions for analysis of attributes related to appearance, aroma, texture and taste.

\subsection{Data analysis}

Consumption preference data were subjected to analysis of variance at $5 \%$ probability by the F test and Tukey's multiple comparison tests $(\mathrm{p} \leq 0.05)$. In the CATA test, the frequency of use of each sensory attribute was determined by counting the number of consumers who used this term to describe each sample, following standard procedures, according to Meyners et al. (2013). The Cochran Q test (Manoukian, 1986) was performed across 28 CATA terms to identify significant differences between structured guava samples Silva et al. (2012). Hierarchical cluster analysis (HCA) was used to compare sensory methodologies by visual inspection of dendograms using Euclidean distance and 
Ward's method, according to Matera et al. (2014). All statistical analyzes were performed by XLSTAT (2018) for Windows (Adinsoft, Paris, France).

\section{Results and discussion}

\subsection{Selection of hydrocolloid concentration through texture acceptance}

There was a significant difference $(\mathrm{p} \leq 0.05)$ between the sample with the lowest concentration of agar, with a soft texture and exudate, and all the others (Table 1).

The samples with higher concentrations of agar were better accepted, but did not present a significant difference $(p>0.05)$ in acceptance between them. The concentration of $0.75 \%$, having higher average value, between the terms "I liked it slightly" and "I liked it moderately", was selected for further studies. It was decided to use the same concentration for the structured fruit produced using gellan gum.

\subsection{Acceptance test}

The use of agar and gellan, with different LA/HA proportions, at the same overall concentration, $0.75 \% \mathrm{w} / \mathrm{v}$, in general did not affect acceptance values (Table 2).

For the attributes appearance, color and aroma, all samples were rated between "neither liked nor disliked" and "liked moderately". On the other hand, for the attributes of flavor, texture and overall acceptance, the values were in the range between "neither liked nor disliked" and "like slightly". The attributes: color, aroma, flavor and overall acceptance showed no significant difference ( $p>0.05)$, between the analyzed samples. However, for appearance and texture there were significant differences.

Table 1. Average values for the acceptance tests of the texture of guava fruit with different concentrations of agar hydrocolloid $(n=60$ panelists; 9 - point hedonic scale ${ }^{*}$.

\begin{tabular}{cc}
\hline Concentration Agar (\%) & Texture \\
\hline 0.25 & $4.250 \pm 2.46^{\mathrm{b}}$ \\
0.50 & $5.734 \pm 2.18^{\mathrm{a}}$ \\
0.75 & $6.266 \pm 2.92^{\mathrm{a}}$ \\
1.00 & $5.844 \pm 1.96^{\mathrm{a}}$ \\
\hline
\end{tabular}

Values with at least one equal letter do not differ at the $5 \%$ level of significance for the Tukey test. ${ }^{\star} 1$ - disliked extremely, 9 - liked extremely.
The lowest scores of 5.3 and 5.54 were obtained respectively for appearance and texture, for the sample LA50/HA50. These values correspond to "neither liked nor disliked" on the hedonic scale, Its appearance acceptance differed significantly $(p<0.05)$ from all the other samples. Panelists reported the presence of exudate and the texture as uneven, sticky and mushy which can justify these values. The acyl groups in the HA gellan gum prevent the approach and association of the polymeric chains, as well as the aggregation of the double helices which occurs on the gel formation process, when HA gellan is used in concentrations exceeding $0.2 \%$. As a consequence, gels produced are weak, flexible and transparent (Noda et al., 2008; Morris et al., 2012). This can explain the characteristics of the gel of the LA50/HA50 sample as it contains a higher proportion of HA. In assessing the overall acceptance and flavor, the averages for all samples were between the hedonic terms "not liked nor disliked" and "like slightly". It is suggested that these scores, a little lower than expected, occurred because consumers associated the structured guava fruits with the sweetened guava paste they know, this may have caused them frustration and influenced the results. In fact, some panelists argued about the absence of sugar in the samples, and made comparisons with the guava paste and not to the fresh guava. However, the goal of the development of fruit bars is to create a product closer to fresh guava without the addition of any sweetner.

\subsection{CATA}

Table 3 shows the results of the CATA test for each attribute available for the description of the four structured guava fruit samples.

From the 28 terms of CATA questions, 9 (Homogenous, Brightness, Yellowish red color, Presence of liquid, Firm, Mushy, Gelatinous, Sticky and Fresh guava flavor) showed significant differences, Cochran $Q$ test $\mathrm{p} \leq 0.05$ (Table 3 ). This values suggest that consumers could not detect differences between the four samples for most tested attributes. Agar and LA100/HA0 samples showed no significant difference ( $p>0.05)$ for all attributes of CATA but differed from LA75/LA25 and HA50/HA50 samples. This suggests that samples with agar and LA100/HA0 formulations are very similar, and in fact the same happended for the sensory evaluation. Homogeneous, Brightness, Pinkish-red color, Guava aroma, and Sour taste were the attributes most frequently marked by consumers. These terms have the highest frequency values, thus they can be pointed to as the terms that mostly described the structured

Table 2. Sensory evaluation results for structured guava fruit $(n=100 \text { panelists; } 9 \text { - point hedonic scale })^{\star}$

\begin{tabular}{ccccc}
\hline \multirow{2}{*}{ Attributes } & \multicolumn{3}{c}{ Samples } \\
\cline { 2 - 5 } & AGAR & LA100/HA0 & LA75/HA25 & LA50/HA50 \\
\hline Appearance & $7.28 \pm 1.41^{\mathrm{b}}$ & $7.20 \pm 1.49^{\mathrm{b}}$ & $6.72 \pm 1.61^{\mathrm{b}}$ & $5.30 \pm 2.23^{\mathrm{a}}$ \\
Color & $7.28 \pm 1.39^{\mathrm{a}}$ & $7.38 \pm 1.33^{\mathrm{a}}$ & $7.28 \pm 1.25^{\mathrm{a}}$ & $6.88 \pm 1.70^{\mathrm{a}}$ \\
Aroma & $6.66 \pm 1.48^{\mathrm{a}}$ & $6.80 \pm 1.47^{\mathrm{a}}$ & $6.73 \pm 1.69^{\mathrm{a}}$ & $6.38 \pm 1.68^{\mathrm{a}}$ \\
Texture & $6.42 \pm 2.00^{\mathrm{b}}$ & $5.86 \pm 2.12^{\mathrm{ab}}$ & $5.69 \pm 2.18^{\mathrm{ab}}$ & $5.54 \pm 2.18^{\mathrm{a}}$ \\
Flavor & $5.73 \pm 1.95^{\mathrm{a}}$ & $5.46 \pm 1.98^{\mathrm{a}}$ & $5.58 \pm 1.93^{\mathrm{a}}$ & $5.52 \pm 2.29^{\mathrm{a}}$ \\
Overall acceptance & $5.97 \pm 1.83^{\mathrm{a}}$ & $5.83 \pm 1.88^{\mathrm{a}}$ & $5.95 \pm 1.85^{\mathrm{a}}$ & $5.53 \pm 2.17^{\mathrm{a}}$ \\
\hline
\end{tabular}

Values, in the same row, with at least one equal letter, do not differ at the $5 \%$ level of significance for the Tukey test. LA = low acyl; HA = high acyl. ${ }^{\star} 1$ - disliked extremely, 9 - liked extremely. 
Table 3. Frequency of CATA terms used by panelists to describe the four structured guava fruit samples and Cochran Q test results for comparison between samples.

\begin{tabular}{|c|c|c|c|c|}
\hline \multirow[b]{2}{*}{ Attributes } & \multicolumn{4}{|c|}{ Samples } \\
\hline & AGAR & $\begin{array}{c}\text { LA100/ } \\
\text { HA0 }\end{array}$ & $\begin{array}{l}\text { LA75/ } \\
\text { HA25 }\end{array}$ & $\begin{array}{l}\text { LA50/ } \\
\text { HA50 }\end{array}$ \\
\hline Homogenous & $63^{\mathrm{b}}$ & $55^{\mathrm{b}}$ & $36^{\mathrm{a}}$ & $23^{\mathrm{a}}$ \\
\hline Brightness & $62^{\mathrm{b}}$ & $62^{\mathrm{b}}$ & $43^{\mathrm{a}}$ & $40^{\mathrm{a}}$ \\
\hline Pale color & $18^{\mathrm{a}}$ & $17^{\mathrm{a}}$ & $9^{a}$ & $8^{\mathrm{a}}$ \\
\hline Pinkish red color & $64^{\mathrm{a}}$ & $71^{\mathrm{a}}$ & $75^{\mathrm{a}}$ & $76^{\mathrm{a}}$ \\
\hline Yellowish red color & $7^{b}$ & $2^{\mathrm{ab}}$ & $5^{\mathrm{ab}}$ & $0^{\mathrm{a}}$ \\
\hline Presence of liquid & $4^{\mathrm{a}}$ & $3^{\mathrm{a}}$ & $10^{\mathrm{a}}$ & $33^{\mathrm{b}}$ \\
\hline Firm & $39^{b}$ & $44^{\mathrm{b}}$ & $28^{\mathrm{ab}}$ & $15^{\mathrm{a}}$ \\
\hline Mushy & $27^{a}$ & $26^{\mathrm{a}}$ & $42^{\mathrm{ab}}$ & $55^{\mathrm{b}}$ \\
\hline Soft & $45^{\mathrm{a}}$ & $31^{\mathrm{a}}$ & $41^{\mathrm{a}}$ & $31^{\mathrm{a}}$ \\
\hline Gelatinous & $49^{b}$ & $43^{\mathrm{ab}}$ & $30^{\mathrm{a}}$ & $33^{\mathrm{ab}}$ \\
\hline Sticky & $5^{\mathrm{a}}$ & $1^{\mathrm{a}}$ & $6^{\mathrm{a}}$ & $16^{\mathrm{b}}$ \\
\hline Adstringent & $6^{\mathrm{a}}$ & $3^{\mathrm{a}}$ & $7^{\mathrm{a}}$ & $5^{\mathrm{a}}$ \\
\hline Sandy & $5^{\mathrm{a}}$ & $10^{\mathrm{a}}$ & $12^{\mathrm{a}}$ & $15^{\mathrm{a}}$ \\
\hline Brittle & $17^{\mathrm{a}}$ & $29^{a}$ & $26^{\mathrm{a}}$ & $23^{\mathrm{a}}$ \\
\hline Juicy & $18^{\mathrm{a}}$ & $12^{\mathrm{a}}$ & $16^{\mathrm{a}}$ & $23^{\mathrm{a}}$ \\
\hline Fruity aroma & $19^{\mathrm{a}}$ & $28^{\mathrm{a}}$ & $33^{\mathrm{a}}$ & $23^{\mathrm{a}}$ \\
\hline Sour aroma & $15^{\mathrm{a}}$ & $17^{\mathrm{a}}$ & $18^{\mathrm{a}}$ & $15^{\mathrm{a}}$ \\
\hline Sweet aroma & $13^{\mathrm{a}}$ & $13^{\mathrm{a}}$ & $14^{\mathrm{a}}$ & $13^{\mathrm{a}}$ \\
\hline Guava aroma & $57^{a}$ & $48^{\mathrm{a}}$ & $49^{\mathrm{a}}$ & $53^{\mathrm{a}}$ \\
\hline Cooked guava aroma & $7^{\mathrm{a}}$ & $11^{\mathrm{a}}$ & $6^{\mathrm{a}}$ & $6^{\mathrm{a}}$ \\
\hline Sour taste & $40^{\mathrm{a}}$ & $41^{\mathrm{a}}$ & $46^{\mathrm{a}}$ & $43^{\mathrm{a}}$ \\
\hline Sweet taste & $10^{\mathrm{a}}$ & $9^{a}$ & $10^{\mathrm{a}}$ & $14^{\mathrm{a}}$ \\
\hline Fruity flavor & $21^{\mathrm{a}}$ & $18^{\mathrm{a}}$ & $19^{\mathrm{a}}$ & $19^{a}$ \\
\hline Guava flavor & $36^{\mathrm{a}}$ & $29^{\mathrm{a}}$ & $34^{\mathrm{a}}$ & $38^{\mathrm{a}}$ \\
\hline Green guava flavor & $18^{\mathrm{a}}$ & $26^{\mathrm{a}}$ & $22^{\mathrm{a}}$ & $14^{\mathrm{a}}$ \\
\hline Cooked guava flavor & $9^{a}$ & $8^{\mathrm{a}}$ & $8^{\mathrm{a}}$ & $10^{\mathrm{a}}$ \\
\hline Fresh guava flavor & $12^{\mathrm{ab}}$ & $5^{\mathrm{a}}$ & $7^{\mathrm{ab}}$ & $14^{\mathrm{b}}$ \\
\hline Strange flavor & $11^{\mathrm{a}}$ & $22^{\mathrm{a}}$ & $19^{\mathrm{a}}$ & $16^{\mathrm{a}}$ \\
\hline
\end{tabular}

Values, in the same row, with equal letters, do not differ at the $5 \%$ level of significance for the Cochran Q test. LA = low acyl; HA = high acyl.

guava fruit formulations. It is noteworthy that the Pinkish-red color attribute was the most selected for all samples. Furthermore, it was observed that Homogeneous and Brightness attributes were more related to the agar and gellan LA100/HA0 samples, while LA50/HA50 were less associated with these attributes. Astringent, Cooked guava aroma, Guava flavor, Yellowish-red color, Sandy, and Sticky were the terms less used to describe the four formulations. The LA50/HA50 formulation presented lump formations and exudation, consistently the terms Presence of liquid and Mushy were mostly assigned to this same sample. Samples with gellan LA75/LA25 and HA50/HA50 presented no significant differences $(\mathrm{p}>0.05)$ for the various attributes of CATA test, except for the terms Presence of liquid and Sticky. As referred above the presence of HA gellan resulted in less homogeneous, less glossy and less firm samples than the other two formulations (agar and LA100/HA0). The CATA results are consistent with the acceptance tests (hedonic scale) presented (Table 2). Panelists prefered firm structured guava fruits samples without visible exsudate. These attributes were present in agar, LA100/HA0 and LA75/ HA25 samples.
Table 4. Average values for each descriptor assessed by ODP for structured guava fruit.

\begin{tabular}{lcccc}
\hline \multirow{2}{*}{\multicolumn{1}{c}{ Attributes }} & \multicolumn{4}{c}{ Samples } \\
\cline { 2 - 5 } & \multirow{2}{*}{ AGAR } & $\begin{array}{c}\text { LA100/ } \\
\text { HA0 }\end{array}$ & $\begin{array}{c}\text { LA75/ } \\
\text { HA25 }\end{array}$ & $\begin{array}{c}\text { LA50/ } \\
\text { HA50 }\end{array}$ \\
\hline Sandy appearance & $3.94^{\mathrm{ab}}$ & $4.97^{\mathrm{a}}$ & $4.54^{\mathrm{a}}$ & $2.93^{\mathrm{b}}$ \\
Brightness & $6.05^{\mathrm{a}}$ & $5.05^{\mathrm{ab}}$ & $3.23^{\mathrm{c}}$ & $3.99^{\mathrm{bc}}$ \\
Presence of bubbles & $3.64^{\mathrm{a}}$ & $3.54^{\mathrm{a}}$ & $2.88^{\mathrm{a}}$ & $2.75^{\mathrm{a}}$ \\
Moist appearance & $3.84^{\mathrm{ab}}$ & $3.30^{\mathrm{b}}$ & $4.37^{\mathrm{ab}}$ & $4.70^{\mathrm{a}}$ \\
Ripe guava aroma & $3.82^{\mathrm{a}}$ & $3.76^{\mathrm{a}}$ & $4.37^{\mathrm{a}}$ & $4.46^{\mathrm{a}}$ \\
Sweet aroma & $4.36^{\mathrm{a}}$ & $3.90^{\mathrm{a}}$ & $3.39^{\mathrm{a}}$ & $3.99^{\mathrm{a}}$ \\
Sandy texture & $3.43^{\mathrm{b}}$ & $6.16^{\mathrm{a}}$ & $5.05^{\mathrm{a}}$ & $3.08^{\mathrm{b}}$ \\
Firm & $3.32^{\mathrm{c}}$ & $6.92^{\mathrm{a}}$ & $5.28^{\mathrm{b}}$ & $3.58^{\mathrm{c}}$ \\
Brittle & $4.39^{\mathrm{ab}}$ & $5.49^{\mathrm{a}}$ & $4.54^{\mathrm{a}}$ & $3.13^{\mathrm{b}}$ \\
Sour taste & $5.68^{\mathrm{a}}$ & $4.99^{\mathrm{ab}}$ & $4.11^{\mathrm{bc}}$ & $3.03^{\mathrm{c}}$ \\
Sweet taste & $5.00^{\mathrm{a}}$ & $4.36^{\mathrm{ab}}$ & $3.77^{\mathrm{b}}$ & $3.21^{\mathrm{b}}$ \\
Guava flavor & $4.98^{\mathrm{a}}$ & $4.99^{\mathrm{a}}$ & $4.23^{\mathrm{a}}$ & $2.99^{\mathrm{b}}$ \\
\hline
\end{tabular}

Values in the same row with equal letters, do not differ at the $5 \%$ level of significance for the Cochran $\mathrm{Q}$ test. The ideal product was not considered in Cochran's $\mathrm{Q}$ test. LA $=$ low acyl; $\mathrm{HA}=$ high acyl.

\subsection{Optimized descriptive profile}

Table 4 summarizes ODP results.

Significant differences $(p>0.05)$ between the samples were encountered for the descriptors analysed. The exception was observed for Presence of bubbles, Ripe guava aroma and Sweet aroma. These results suggest that consumers showed less capacity to discriminate these characteristics; however, this fact may be related to consumers' lack of understanding of the meaning of the descriptors. There are significant differences $(\mathrm{p}<0.05)$ for the descriptor Sandy appearance between sample LA50/HA50 and samples LA100/HA0 and LA75/HA25, which do not differ statistically $(p>0.05)$ from each other. Possibly, the presence of a higher concentration of LA gellan can contribute to this difference. It can be also seen in Table 4 that the values for Sandy appearance are consistent with those for descriptor Sandy texture. The agar sample received the higher average score of 6.05 for the Brightnessness attribute, which can be considered positive. The high Brightnessness of the sample may be associated with loss of water. The agar samples also received, the highest intensity scores for the attributes Sweet taste and Sour taste, although not significantly different from those for LA100/HA0, which is reflected in the shaper picks, observed on the spider chart (Figure 1).

On the other hand, it received lower scores for Firm and Sandy texture attributes. According to Schiavi et al. (2016), agar gels may be subject to relevant degradation if not preserved in a temperature controlled environment. The increase of temperature during the experiment, may have caused changes in gel structure and loss of water. The LA50/HA50 sample presented the higher average value (3.84), regarding the descriptor Moist which is consistent with the CATA results (Table 3 ) and was previously justified with the higher concentration of HA gellan. On the other hand, the LA100/HA0 sample presented the lower value for the Moist descriptor. According to Morris et al. (2012) in gels with high LA gellan concentrations the loss of liquid during 
the maturation period does not occur, being stable when stored at room temperature or under refrigeration. The Firm texture differed significantly from all the other samples and the Brittle texture showed a significant difference only in relation to the LA50/HA50 sample.

\subsection{Comparison of the sensory methodologies}

Figure 2a-c shows the dendrogram obtained by the Hierarchical Cluster Analysis (HCA) for the three methods used (Sensory Acceptance, CATA and ODP tests).
The dendrogram for the sensory acceptance test (Figure 2a) shows a higher similarity between the two samples with higher concentration of LA gellan (LA100/HA0 and LA75/HA25). However the agar sample, which showed characteristics close to the LA100 / HA0 and LA75 / HA25 formulations appears in a different group. When analyzing the CATA dendrogram (Figure 2b), the presence of three distinct segments can be seen, the first follow-up (Group 1) formed by the samples LA100/HA0 and LA75 / HA25, followed by the agar sample and a third follow-up with the LA50/HA50 sample. Apparently in this method the tasters also identified the samples having higher

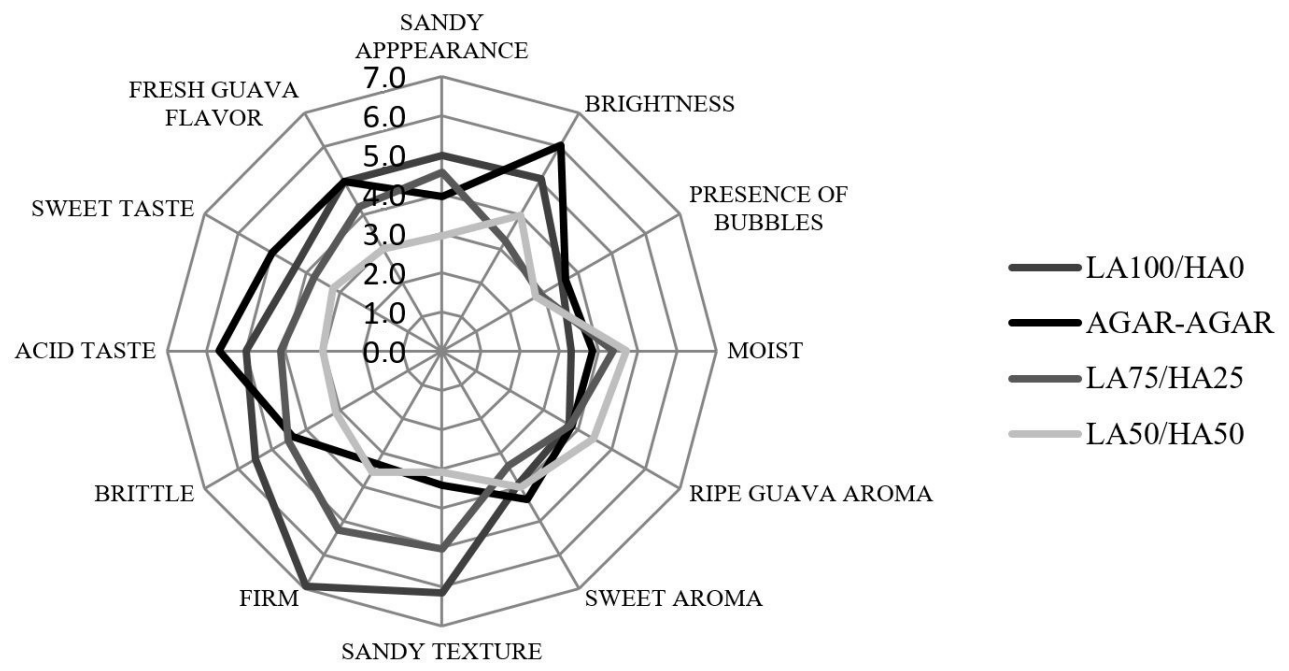

Figure 1. Spider-graph representative of ODP descriptors for the four formulations of structured guava fruit quantified using a $9 \mathrm{~cm}$ scale. LA = low acyl; HA = high acyl.
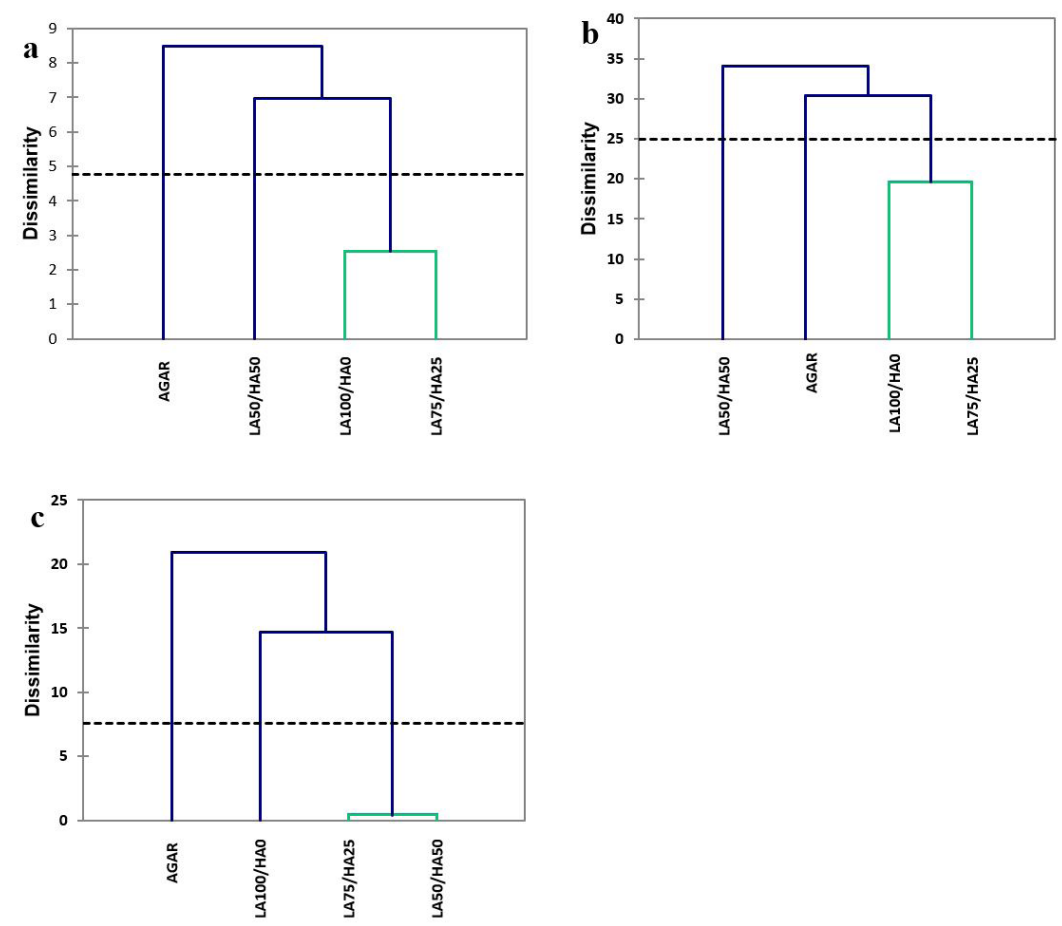

Figure 2. Dendrogram obtained by Hierarchical Clustering Analysis of acceptance test. (a) Sensory Acceptance; (b) CATA; and (c) ODP of the structured guava fruit samples. LA = low acyl; HA = high acyl. 
concentrations of gellan LA as being more similar. The ODP dendogram (Figure 2c), also shows three groups. Group 1 formed by samples LA75/HA25 and LA50 / HA50, Group 2, by the sample LA100/HA0, and a third group formed by the agar simple. This suggestes that the trained panel was able to relate the samples based on the type of hydrocolloid (agar and gellan), and distinguish the samples based on the concentrations of HA, and thus in Group 3 are the samples with the presence of HA gellan which were considered identical.

Given the above, there is still a need for more sensory studies for the evaluation of structured guava fruits. Since, being a new product, the characterization by projective methods is an additional approach to analyze the samples in greater depth, clearly demonstrating the feeling, thinking and perception of the consumers (Gambaro, 2018). These methods have been used in studies with several foods, such as meat (Andrade et al., 2016) crackers (Morin et al., 2018) and fermented milk (Pinto et al., 2018).

\section{Conclusion}

Structured fruits guava samples (with Agar, LA100/HA0, LA75/HA25 and LA50/HA50 were analyzed using three different methodologies. The sensory acceptance analysis showed slight variation. The CATA analysis showed the preference of the panelists for Agar, LA100/HA0 and LA75/HA25 formulations, particularly for the first two which were perceived as iddentical by the panelists.With the Optimized Descriptive Profile, the characteristics that most stood out were Brightness, Sweet taste, Guava flavor, Firm and Sandy text ure. Comparing the three methods evaluated, it was verified that with the CATA and sensory acceptance tests, the tasters did not identify differences between the samples in relation to the type of hydrocolloid but with the ODP test they could iddentify this difference.

\section{References}

Andrade, J. C., Aguiar Sobral, L., Ares, G., \& Deliza, R. (2016). Understanding consumers' perception of lamb meat using free word association. Meat Science, 117, 68-74. http://dx.doi.org/10.1016/j. meatsci.2016.02.039.

Avery, N. G., \& Joseph, A. D. (2019). Use of rating scales versus checkall-that-apply ballots in quantifying strain-specific Cannabis aroma. Journal of Sensory Studies, 34, 1-7.

Azoubel, P. M., Araújo, A. J. B., Oliveira, S. B., \& Amorim, M. R. (2011). Restructuring Passiflora cincinnata fruit pulp: influence of hydrocolloids. Food Science and Technology, 31(1), 160-166. http:// dx.doi.org/10.1590/S0101-20612011000100023.

Bonneau, A., Boulanger, R., Lebrun, M., Maraval, I., Valette, J., Guichard, É., \& Gunata, Z. (2018). Impact of fruit texture on the release and perception of aroma compounds during in vivo consumption using fresh and processed mango fruits. Food Chemistry, 239(15), 806-815. http://dx.doi.org/10.1016/j.foodchem.2017.07.017. PMid:28873638.

Chandrasekaran, R., \& Radha, A. (1995). Molecular architectures and functional properties of gellan gum and related polysaccharides. Trends in Food Science \& Technology, 6(5), 143-148. http://dx.doi. org/10.1016/S0924-2244(00)89022-6.

Danalache, F., Beirão-Da-Costa, S., Mata, P., Alves, V. D., \& MoldãoMartins, M. (2015). Texture, microstructure and consumer preference of mango bars jellified with gellan gum. Lebensmittel-Wissenschaft + Technologie, 62(1), 584-591. http://dx.doi.org/10.1016/j.lwt.2014.12.040.

Danalache, F., Carvalho, C. Y., Alves, V. D., Moldão-Martins, M., \& Mata, P. (2016). Optimisation of gellan gum edible coating for ready-to-eat mango (Mangifera indica L.) bars. International Journal of Biological Macromolecules, 84, 43-53. http://dx.doi.org/10.1016/j. ijbiomac.2015.11.079. PMid:26657585.

Faria, E. V., \& Yotsuyanagi, K. (2008). Técnica de análise sensorial (2nd. ed.) Campinas: ITAL.

Gambaro, A. (2018). Projective techniques to study consumer perception of food. Current Opinion in Food Science, 21, 46-50. http://dx.doi. org/10.1016/j.cofs.2018.05.004.

Jaeger, S. R., Hunter, D. C., Vidal, L., Chheang, S. L., Ares, G., \& Harker, F. R. (2019). Sensory product characterization by consumers using check-all-that-apply questions: investigations linked to term development using kiwifruit as a case study. Journal of Sensory Studies, 23(3), 1-13. http://dx.doi.org/10.1111/joss.12490.

Manoukian, E. B. (1986). Mathematical nonparametric statistics. New York: Gordon and Breach.

Matera, J. A., Cruz, A. G., Raices, R. S. L., Silva, M. C., Nogueira, L. C., Quitério, S. L., Cavalcanti, R. N., Freiras, M. Q., \& Conte, C. A. Jr. (2014). Discrimination of Brazilian artisanal and inspected pork sausages: application of unsupervised, linear and non-linear supervised chemometric methods. Food Research International, 64, 380-386. http://dx.doi.org/10.1016/j.foodres.2014.07.003. PMid:30011664.

Meilgaard, M. C., Civille, V. G., \& Carr, B. T. (2006). Sensory evaluation techniques (4th ed.). Boca Raton: CRC Press. http://dx.doi.org/10.1201/ b16452.

Meyners, M., Castura, J. C., \& Carr, B. T. (2013). Existing and new approaches for the analysis of CATA data. Food Quality and Preference, 30(2), 309-319. http://dx.doi.org/10.1016/j.foodqual.2013.06.010.

Meyners, M., Castura, J. C., Varela, P., \& Ares, G. (2014). Novel techniques in sensory characterization and consumer profiling check-all-thatapply questions (pp. 271-305). Boca Raton: CRC Press. http://dx.doi. org/10.1201/b16853-12.

Morin, M., Hayward, L., \& McSweeney, M. B. (2018). Use of experienced panelists and the projective mapping task in comparison to trained panelists and naïve consumers. Journal of Sensory Studies, 33(6), e12463. http://dx.doi.org/10.1111/joss.12463.

Morris, E. R., Nishinari, K., \& Rinaudo, M. (2012). Gelation of gellan: a review. Food Hydrocolloids, 28(2), 373-411. http://dx.doi.org/10.1016/j. foodhyd.2012.01.004.

Noda, S., Funami, T., Nakauma, M., Asai, I., Takahashi, R., Al-Assaf, S., Ikeda, S., Nishinari, K., \& Phillips, G. O. (2008). Molecular structure of gellan gum imaged with atomic force microscopy in relation to the rheological behaviour in aqueous systems. 1. Gellan gum with various acyl contents in the presence and absence of potassium. Food Hydrocolloids, 22(6), 1148-1159. http://dx.doi.org/10.1016/j. foodhyd.2007.06.007.

Petrovski, S., \& Tillett, D. (2012). Back to the kitchen: food-grade agar is a low-cost alternative to bacteriological agar. Analytical Biochemistry, 429(2), 140-141. http://dx.doi.org/10.1016/j.ab.2012.07.011. PMid:22809873.

Pinto, L. P. F., Silva, H. L. A., Kuriya, S. P., Maçaira, P. M., Oliveira, F. L. C., Cruz, A. G., Esmerino, E. A., \& Freitas, M. Q. (2018). Understanding perceptions and beliefs about different types of fermented milks through the application of projective techniques: a case study using Haire's shopping list and free word association. Journal of Sensory Studies, 33(3), e12326. http://dx.doi.org/10.1111/joss.12326. 
Pramudya, R. C., \& Seo, H. S. (2018). Using Check-All-That-Apply (CATA) method for determining product temperature-dependent sensory-attribute variations: a case study of cooked rice. Food Research International, 105, 724-732. http://dx.doi.org/10.1016/j. foodres.2017.11.075. PMid:29433267.

Schiavi, A., Cuccaro, R., \& Troia, A. (2016). Strain-rate and temperature dependent material properties of Agar and Gellan Gum used in biomedical applications. Journal of the Mechanical Behavior of Biomedical Materials, 53, 119-130. http://dx.doi.org/10.1016/j. jmbbm.2015.08.011. PMid:26318572.

Silva, R. C. S. N., Minim, V. P. R., Silva, A. N., Peternelli, L. A., \& Minim, L. A. (2014). Optimized descriptive profile: How many judges are necessary? Food Quality and Preference, 36, 3-11. http://dx.doi. org/10.1016/j.foodqual.2014.02.011.

Silva, R. C. S. N., Minim, V. P. R., Simiqueli, A. A., Moraes, L. E. S., Gomide, A. I., \& Minim, L. A. (2012). Optimized descriptive profile: a rapid methodology for sensory description. Food Quality and Preference, 24(1), 190-200. http://dx.doi.org/10.1016/j. foodqual.2011.10.014.
Stone, H., \& Sidel, J. L. (2004). Sensory evaluation practices (3rd ed.). New York: Academic Press.

Vidal, L., Antúnez, L., Ares, G., Cuffia, F., Lee, P.-Y., Le Blond, M., \& Jaeger, S. R. (2019). Sensory product characterisations based on check-allthat-apply questions: further insights on how the static (CATA) and dynamic (TCATA) approaches. Food Research International, 125, 108510. http://dx.doi.org/10.1016/j.foodres.2019.108510. PMid:31554131.

Vidal, L., Tárrega, A., Antúnez, L., Ares, G., \& Jaeger, S. R. (2015). Comparison of Correspondence Analysis based on Hellinger and chi-square distances to obtain sensory spaces from check-all-thatapply (CATA) questions. Food Quality and Preference, 43, 106-112. http://dx.doi.org/10.1016/j.foodqual.2015.03.003.

Waehrens, S. S., Gronbeck, M. S., Olsen, K., \& Byrne, D. V. (2018). Impact of consumer associations, emotions, and appropriateness for use on food acceptability: a CATA and liking evaluation of vegetable and berry beverages. Journal of Sensory Studies, 33(4), e12328. http://dx.doi.org/10.1111/joss.12328.

XLSTAT. (2018). Complemento de software estatístico e de análise de dados para Excel, versão 2.0. Paris: Adinsoft 